\title{
De Heliodoro a Tasso y a ¿Cervantes?
}

\author{
Máximo Brioso Sánchez. \\ Universidad de Sevilla \\ Héctor Brioso Santos \\ Universidad de Alcalá de Henares
}

\begin{abstract}
RESUMEN
En este artículo se compara detenidamente un pasaje de Teágenes y Cariclea de Heliodoro, el del nacimiento de Cariclea, con otro de la Gerusalemme liberata de Torcuato Tasso y ambos con la escena correspondiente de la refundición teatral española anónima. La conquista de Jerusalén, conservada en la Biblioteca de Palacio y descubierta y editada hace tres lustros por $S$. Arata. La conclusión a que llegamos es la de que el anónimo teatral español conoce e imita sólo la versión de Tasso, lo que corrobora, si se trata de un texto cervantino, como es más que probable, que su fecha es muy temprana, en torno a 1581.

Palabras clave: literatura comparada, Heliodoro, Tasso, Cervantes.

ABSTRACT

In this paper we aim to constrast an excerpt from Heliodoros's Theagenes and Charikleia, Charikleia's birth, with a section from Tasso's Gerusalemme liberata, and both texts with a passage from the anonymous play La conquista de Jerusalén, as kept in a manuscript from the Biblioteca de Palacio, discovered and published fifteen years ago by $S$. Arata. Our conclusion is that the anonymous author of the Spanish play only knows and imitates Tasso's text. So, if it is in fact a Cervantine work, as it seems very probable, its date could be a very early one, circa 1581
\end{abstract}

Keywords: Comparative Literature, Heliodoros, Tasso, Cervantes.

Decir hoy que Torquato Tasso utilizó en su Gerusalemme liberata materiales extraídos de Teágenes y Cariclea de Heliodoro sería descubrir a estas alturas el Mediterráneo. Ya en su edición comentada de Pavía (Bartoli, 1592), el erudito Guastavini lo señaló, menos de veinte años después del final de la redacción de la Gerusalemme, y su observación se ha venido repitiendo edición tras edición. Todavía entre nosotros, en la discreta traducción de L. M. (sic) en Editorial Iberia (Barcelona, 1984) aparece esta explicación, aquí extractada: "La primera parte de la historia de Clorinda, tal cual la refiere Tasso, es una imitación de los Etiópicos, de Heliodoro... Nada ofrece de extraño que Tasso tomase su historia de Clorinda de aquel escritor, si se atiende a que la traducción de los Etiópicos de Amyot, anterior en algunos años a la aparición de la Jerusalén gozaba de 
una reputación inmensa en Francia cuando Tasso hizo su viaje a la Corte de Carlos IX"1.

No tenemos nada que objetar a esta nota, pero debemos matizar esa referencia tan directa a la traducción de Amyot. En efecto, cuando Tasso termina la redacción de su poema en 1575, no sólo estaban disponibles la editio princeps de Etiópicas (Basilea 1534) de Opsopopeus, la versión al latín de 1552, sino la traducción tan celebrada de J. Amyot al francés (1547) y, para mayor abundamiento, la italiana de Leonardo de Ghini (1559) y todavía otra en la misma lengua, la de Génova, 1569. O, de otro modo, ni siquiera es seguro que Tasso tuviera que esperar a su viaje francés para deleitarse con el texto vertido por Amyot y extraer de él la inspiración para emular a Heliodoro. Y es que si Tasso imita a Heliodoro, no lo hace de un modo mostrenco, y no es sorprendente que sea $a s^{2}{ }^{2}$. Heliodoro, como sabemos, fue un ídolo literario de la época y en muy diversos países. En España todos recordamos los elogios del Pinciano en su Filosofía Antigua Poética (1596) y cómo Cervantes vuelve a emularlo en su Persiles.

Tasso, como era esperable, imita a Heliodoro cristianizándolo. Como hace con Virgilio. La poderosa guerrera Clorinda, ya en el canto segundo del poema, muestra su piedad en el episodio de Sofronia y Olindo, como anticipando su tardía conversión al borde mismo de la muerte. Clorinda, como los típicos héroes y heroínas de Ariosto y los caballeros andantes, errabundos en sus sucesivas empresas, viene de Persia ("le contrade perse", 2.41.1) cuando arriba a Jerusalén para contribuir a la defensa de la ciudad amenazada por la hueste cristiana de Goffredo. Nada parece ligarla a la lejana Etiopía; será esa emulación la que lo logre. No hay en el poema ninguna alusión a su origen etíope hasta que se cuenta su nacimiento en el canto doce. O Tasso ha querido crear en éste un profundo efecto de sorpresa o tal vez en su redacción comenzó sin tener claro qué origen le daría a su heroína, aunque sí es muy verosímil que imaginara ya esa conversión. La Cariclea de Heliodoro facilitaba la emulación: ya en la novela griega aparece como recia combatiente, una novedad en el antiguo género, en el que las protagonistas son castas y fieles a su único amor, se defienden como pueden de los acosos eróticos, pero no gastan esta estampa de luchadoras. Y también Tasso tenía un modelo en la Camila del canto XI de la Eneida virgiliana, y lo aplica por igual en la belicosa cristiana Gildippe. La epopeya renacentista está plagada de mujeres heroicas y dadas a las armas, así que no había ninguna necesidad de esperar a la influencia de Heliodoro para recoger ese talante marcial de su Cariclea. Es la fábula portentosa de su nacimiento la que atrae al poeta de Bérgamo, su relativamente original

\footnotetext{
${ }^{1}$ En nota 97 del traductor al canto XII.

2 Llama sin embargo la atención que algún editor de la Gerusalemme de Tasso llegue a escribir que "il racconto di Arsete è d'invenzione. E tuttavia rivela qualche punto di contatto con le Istorie Etiopiche di Heliodoro d'Emesa...": así L. Caretti (Torino, Einaudi, 1993 [1971], p. 362, n. 21). La presencia de Heliodoro en Tasso es muy notable, a pesar de todas las simplificaciones y los cambios introducidos por el poeta italiano.
} 
planteamiento, sólo que Tasso no lo sigue en las posteriores andanzas y en el retorno final a la patria etíope y el feliz reconocimiento de sus padres. La trayectoria de Clorinda será muy distinta y su destino se fija en su muerte en combate bajo los muros de la ciudad santa y -¿cómo no?- en su conversión. La atmósfera neoplatónica, el idealismo de Heliodoro facilitaban la construcción de su figura, incluso ese franquear postrero el umbral del Cristianismo.

Por tanto, nada que objetar en lo que se refiere a Tasso, ningún descubrimiento, sino lo contrario, si acaso: que su emulación de Heliodoro, como la de Virgilio, era casi inevitable. Heliodoro había escrito, aunque en prosa griega, una epopeya. Pero, por supuesto, introduce novedades: además de otros pormenores, los padres de Clorinda no serán ya los reyes paganos Persina e Hidaspes ${ }^{3}$, sino unos monarcas cristianísimos que siguen "del figlio di Maria la legge" (12.21.3); el famoso cuadro que provoca el milagro del color de la futura Cariclea no representa el mito pagano de Perseo y Andrómeda, sino una anónima "vergine" (12.23.3) atacada por un dragón y defendida por un misterioso "cavalier"4. Tampoco quien acoge a la niña expuesta será el fiel y sabio sacerdote Sisimitres de Heliodoro, sino el devoto eunuco Arsete, el cual, sin embargo, recalcitrante pagano, demorará hasta no cumplir el ruego de la reina etíope de que su hija sea bautizada. Y desde luego Tasso no incluye en su texto la figura excepcional ni la función narrativa de Calasiris.

La impresión que extrae un atento lector es que Tasso adoptó el motivo del nacimiento de Clorinda como podía haber adoptado otro cualquiera o ninguno. En otras palabras, que fue sólo la emulación de Heliodoro la que lo llevó a incrustar ese pasaje en su poema, sin que el desarrollo de éste diera pie con otros lazos a la necesidad de su inclusión. Pero crea, no obstante, un precedente que tendrá ecos en otros relatos posteriores, pero siempre con la duda de si esas imitaciones parten del modelo del poeta italiano o se apoyan de modo directo total o parcialmente en la novela de Heliodoro. Por ejemplo, es claro que cuando Cervantes, muchos años después y ya en pleno Barroco, escribe su Persiles parte de un modo claro de Heliodoro, al que conoce y aprecia de tiempo atrás. Nosotros hemos defendido que la presencia de ecos simultáneos de Heliodoro y de Virgilio en el Persiles, como en Tasso, dentro de la boga de la presencia de la novela de aquél entre los círculos ilustrados de países como Italia y España, "es extremadamente coherente... y representa un empeño indudablemente dignificador en el texto cervantino" 5 . Y esto porque no se

${ }^{3}$ El padre será Senapo, nombre de curiosa trayectoria en la nueva épica italiana: está ya en el Orlando de Ariosto y también como soberano cristiano de Etiopía (cf. 12.102).

${ }^{4}$ Es de suponer que es el mismo guerrero (“celeste guerrier”) que luego se le aparece por dos veces en sueños al eunuco en cuyas manos fue confiada Clorinda (12.36 y 39), es decir, san Jorge.

${ }^{5}$ M. Brioso Sánchez y H. Brioso Santos, "Sobre la problemática relación entre Heliodoro y el Persiles y Sigismunda de Cervantes: el motivo de la comunicación lingüística", Criticón, 86 (2002), pp. 73-96 (cita de p. 74). 
trata sólo de una novela inspiradora y por tanto propicia a ser emulada por sus virtudes literarias; es también una prueba práctica de lo que teorizó Aristóteles. Y de ahí su doble prestigio en el Renacimiento y en el Barroco.

Pero no hay que esperar a que Cervantes planee y redacte su Persiles para que se muestre en él un cierto peso de la obra de Heliodoro. Desde que aparece la del Pinciano cualquier autor español ilustrado podía caer en la tentación de leer por el medio que fuese a Heliodoro, y existían muchos, y no hay duda de que Cervantes lo hizo. Hemos aportado argumentos de que, en efecto, fue así y de que el alcalaíno debió conocer al novelista griego cuando estaba ya redactando al menos los últimos capítulos de la Primera Parte del Quijote, y hemos escrito lo siguiente: "Si bien hemos mostrado que otros posibles argumentos para una supuesta influencia de Heliodoro en la Primera Parte no nos son aceptables, se trata, al fin y al cabo, de indicios negativos que no la excluyen y esto es del todo compatible con una fecha relativamente tardía para todos aquellos otros textos y desde luego ya para una meditada lectura de la obra del Pinciano, de la que hay un claro reflejo en el discurso del canónigo toledano. No puede ser tampoco un azar que tanto la 'Historia del cautivo' como las disquisiciones sobre la poesía en prosa y la posible redención de las historias de aventuras caballerescas se lean cerca del término de esa Primera Parte. Estaríamos ya en el tiempo de su redacción, bien dentro del siglo XVII, cuando se acrecienta la popularidad de Heliodoro, a la que Cervantes contribuirá de un modo sin duda decisivo"6.

En los textos citados la presencia de Heliodoro en Cervantes es directa. Podrá deberse su lectura al influjo de las teorías del maestro vallisoletano, pero es claro que Cervantes no sólo lee a Heliodoro, sino que lo relee hasta empaparse no ya de ciertas notas novedosas de su texto, también de su espíritu innovador y de la profundidad de los planteamientos literarios del novelista.

Pues bien, como saben hoy todos los hispanistas, no hace mucho tiempo que se ha reencontrado un texto supuestamente cervantino, una pieza teatral, La conquista de Jerusalén ${ }^{7}$, en la que basta una primera lectura para percatarse también de la

6 M. Brioso Sánchez y H. Brioso Santos, "De nuevo sobre Cervantes y Heliodoro. La comunicación lingüística y algunas notas cronológicas”, Cervantes, 23.2 (2003), pp. 297-341 (cita de pp. 336 s.).

${ }^{7} \mathrm{El}$ texto puede verse en S. Arata, "La Conquista de Jerusalén, Cervantes y la generación teatral de 1580”, Criticón, 54 (1992), pp. 9-112 (edición por la que citamos, dado que es la más asequible). Fue también publicado, sin cambio alguno, por el mismo Arata en "Edición de textos y problemas de autoría: el descubrimiento de una comedia olvidada", artículo incluido en J. Canavaggio, ed., La comedia. Seminario bispano-francés organizado por la Casa de Velázquez. (Madrid, diciembre de 1991-junio 1992), Madrid, Casa de Velázquez, 1995, pp. 51-76. Más tarde, ya fallecido el joven hispanista italiano, una versión ligeramente corregida de ese texto, con idéntico título al del artículo original de 1992, fue publicada en el volumen de homenaje póstumo editado por su hermana y sus antiguos colegas y amigos: F. Antonucci, L. Arata y M. 
influencia de Heliodoro, pero -y éste es el detalle llamativo- no por fuerza directa, sino quizás más bien o básica o absolutamente, lo que está por ver, a través del conocimiento del poema de Torquato Tasso.

La autoría de este nuevo texto fue objeto de estudio por su primer descubridor, en torno a 1990, en la Biblioteca del Palacio Real de Madrid, el malogrado profesor e investigador italiano Stefano Arata. Este descubrimiento fue desvelado a los investigadores al año siguiente, durante un seminario de la Casa de Velázquez organizado por Jean Canavaggio y publicado, como se ha dicho, en Criticón en 1992. El brillante profesor de Pisa atribuyó la obra ya entonces, aunque con grandes precauciones, a un autor de la generación teatral española de 1580 y a Miguel de Cervantes en particular. Los argumentos manejados entonces por Arata eran incisivos y de gran precisión, hasta el punto de que, aunque -todo hay que decirlo- no han sido demasiadas las reacciones críticas ante su descubrimiento ${ }^{8}$, un especialista en las atribuciones cervantinas como José Montero Reguera aceptaba tres años después ${ }^{9}$ buena parte de las razones del italiano para tal atribución, con alguna excepción de escasa importancia, como la suposición que Arata hiciera sobre la posible presencia tácita de Felipe II tras el personaje de Godofre de Bullón, una idea que, según Montero, penetraba "en un terreno quizá demasiado especulativo, no necesario para defender la posible autoría cervantina" (p. 53). Pese a este reparo de poca monta y que poco tiene que ver con el problema de la autoría, Montero Reguera dictaminaba entonces: "Los argumentos aportados por Arata -en especial los cuatro primeros- no permiten defender de modo taxativo la autoría cervantina del manuscrito de la Biblioteca de Palacio, pero proporcionan a esta hipótesis una amplia verosimilitud. Haría falta a este respecto un exhaustivo cotejo textual con otras obras de Cervantes a resultas del cual quizás se pudieran aportar nuevas pruebas favorecedoras de esta conjetura" (ibid.).

En suma, dado que la copia de la comedia aparece sin nombre ni fecha, en teoría puede ser obra de cualquiera de los contemporáneos de Cervantes o de él mismo, aunque numerosos indicios, no todos ellos refutables, señalan al escritor de Alcalá, y en especial su confidencia al lector de la "Adjunta al Parnaso", hecha en medio de un muy sabroso diálogo entre Pancracio de Roncesvalles y un alter ego de Miguel de Cervantes:

del V. Ojeda, Textos, géneros, temas. Investigaciones sobre el teatro del Siglo de Oro y su pervivencia, Pisa, Edizioni ETS, 2002, pp. 31-126.

${ }^{8}$ Con alguna excepción: J. Maestro, en su entrada "Miguel de Cervantes" de J. Huerta Calvo, dir., Historia del teatro español, Madrid, Gredos, 2003, vol. I, pp. 757-782 (cita en p. 771), resume sin discutirlos los argumentos del descubrimiento de Arata y en principio parece no descartar esta comedia en el corpus cervantino.

9 "La obra literaria de Miguel de Cervantes (ensayo de un catálogo)", en Anthony Close et alii, Cervantes, Alcalá de Henares, Centro de Estudios Cervantinos, 1995, pp. 43-71. 
- ¿Y vuesa merced, señor Cervantes -dijo él-, ha sido aficionado a la carátula? ¿Ha compuesto alguna comedia?

-Sí -dije yo-, muchas; y a no ser mías, me parecieran dignas de alabanza, como lo fueron Los Tratos de Argel, La Numancia, La gran Turquesca, La Batalla Naval, La Jerusalén, La Amaranta o la del Mayo, El Bosque Amoroso, La Única y La Bizarra Arsinda, y otras muchas de que no me acuerdo. Mas la que yo más estimo y de la que más me precio fue y es de una llamada La Confusa, la cual, con paz sea dicho de cuantas comedias de capa y espada hasta hoy se han representado, bien puede tener lugar señalado por buena entre las mejores ${ }^{10}$.

Desde luego sorprende que los cervantistas apenas reaccionasen -con la salvedad indicada- ante este trascendente descubrimiento de un supuesto inédito cervantino, que hace justicia al cabo de cuatro siglos a la famosa alusión de Cervantes a una obra suya titulada precisamente La Jerusalén, que se ha creído perdida desde entonces, un llamativo despiste de la crítica que cabe atribuir sin duda al poco interés y los muchos prejuicios que suele despertar la producción teatral cervantina.

La obra se presenta a sus raros lectores modernos como una pieza, en copia manuscrita de 2635 versos distribuidos en tres jornadas de extensión desigual, una característica que, como ya observase Arata en 1992, permite suponer con certeza que la comedia estuvo en su origen dividida, al uso de esos años, en cuatro jornadas, y que después la tercera y la cuarta fueron suturadas en una sola, de forma parecida a como lo fueron otras piezas en las décadas posteriores y para adaptarlas a la nueva moda de las tres jornadas o actos (1992, p. 11).

En cuanto a la fecha, sin extendernos más en estos detalles ecdóticos e internos, nos importa aclarar que Arata ya indicó que la obra podía, "con cierta seguridad", datarse "entre 1581 y 1582" (1992, p. 12). Y, en efecto, tanto la métrica como el gran número de personajes del reparto, las todavía reconocibles cuatro jornadas de la redacción original, el estilo en general y el asunto mismo, propio de los ochenta, en plenas convulsiones político-militares de esos años centrales del reinado filipino, confirman esta suposición del profesor italiano. La obra no puede pertenecer al XVII, ya que no hay en su reparto un gracioso. Sus hechuras dramáticas y métricas, sus personajes alegóricos y otros aspectos nos permiten fecharla a grandes rasgos en la octava década del siglo XVI. Igualmente, la alta proporción de versos italianos de la pieza anónima, como ya señaló Arata, indica su fecha "muy temprana", aunque la tirada en romance que aquí nos interesa la moderniza en apariencia, una tirada que pudo ser añadida con posterioridad a partir de la reescritura de unas redondillas

${ }^{10}$ Viaje del Parnaso, Poesías completas, V. Gaos, ed., Madrid, Castalia, 1973, I, pp. 182-183. 
preexistentes en la primera versión (de nuevo 1992, p. 14). Y, de hecho, el fondo teatral de Palacio es anterior a 1600 y contiene obras de autores de la generación de 1580 y de un bisoño Lope de Vega.

Por otro lado, esta comedia tendría que ser posterior a febrero de 1581 (Ferrara, Febo Bonà), momento en que Tasso publicó su Gerusalemme completa, aunque llevara trabajando en ella al menos desde $1574^{11}$. El poema debía estar completo hacia el año 1575, tras una rapidísima e inspirada composición. Su autor hizo circular partes de él, para que fuesen leídas por los críticos, desde 1576 y, más tarde, en un tentativo Goffredo, aparecido en 1580. De ser Cervantes el creador de la citada pieza teatral, parece demasiado aventurado pensar que llegase a tener noticia del poema en sus primeras versiones, antes de su publicación, pese a que en esos años residiera en Italia (hasta septiembre del 75, con temporadas en Palermo y Nápoles, interrumpidas por expediciones militares) ${ }^{12}$.

En fin, los paralelos con las obras de Cervantes que detallaremos en un futuro estudio no sólo permiten hacer conjeturas creíbles sobre su autoría, sino además sobre su fecha, pues acotan una cronología aproximada de la primera mitad de los años ochenta del siglo XVI.

Aunque en líneas generales poema y comedia se parecen bastante, se produjo una clara reelaboración o refundición del argumento tassiano en manos del autor anónimo. La propia Gerusalemme de Torquato Tasso, que él tendía a llamar Goffredo, fue objeto de una labor obsesiva de reescritura, característica de un poeta inseguro y proclive a tener en cuenta los comentarios de lectores cualificados. Siendo como era un autor más dotado para la literatura novelesca, amorosa y pastoril que para la epopeya de exaltación cristiana, es de esperar que incurriese no sólo en algunos deslices, sino que se emplease a fondo en la redacción en las posibilidades novelescas y aventureras de la historia. Según señalara la clásica Historia de la literatura italiana de K. Vossler, por ejemplo, "el asunto del poema, la conquista de Jerusalén por el ejército de la primera cruzada, requería un arte viril, rigurosamente histórico e inspirado en sentimientos piadosos. Pero la buena voluntad de Tasso de poco servía en este asunto (...). Las bellezas duraderas de la obra de Tasso, sin embargo, son de muy diferente especie: son sus numerosos episodios, en particular las historias de amor, las descripciones idílicas, los caracteres muelles y sentimentales, la lírica melancólica, voluptuosa y delicuescente que se halla, por decirlo así, derramada por todo el poema. La unidad de la acción es sólo superficial y no coincide con la unidad del

${ }^{11}$ Para la información sobre las fechas de la vida y obra tassiana puede verse la "Introduzione" de Francesco Flora a su magna edición de las Poesie de Tasso, Milán-Nápoles, Ricardo Ricciardi Editore, 1952, especialmente pp. xliii-xliv.

12 Para las fechas de la biografía cervantina nos guiamos por el "Resumen cronológico" de Jean Canavaggio incluido en la edición de Don Quijote de la Mancha, F. Rico, dir., Barcelona, Crítica, 1998, vol. I, pp. ccxliii-cclxxi. 
interés poético; aquélla gravita en torno a la conquista de Jerusalén; ésta, en torno a todas las acciones secundarias que salen al paso estorbando y cohibiendo la narración (...). A decir verdad, la unidad del conjunto está constituida por un espíritu idílico y elegíaco (...)"13.

Ante estas indudables fallas constructivas, que pueden perdonársele a un genial poema épico pero no a un drama, el anónimo de la década de los ochenta tiene que segar en flor las ricas descripciones y los amenos intermedios amorosos del imaginativo y sensual Tasso para articular mejor su acción teatral y reforzar el sentimiento cristiano que pretende ensalzar. Con esas miras, el argumento original se ha reducido de modo notable en la adaptación teatral, lógicamente mucho más corta que el poema tassiano. En general muchos episodios duplicados o complejos de éste se simplifican. El autor español ha eliminado numerosos personajes y episodios (Dudón, Aleto, el ya citado mago Ismeno, Ubaldo, la historia de Rinaldo y Armida, Vafrino, Odoardo, Otón, Guelfo...). Cuando el argumento dramático comienza, de modo característico in medias res, el ejército cristiano ya se ha agrupado ante los muros de la ciudad, mientras que en el poema de Tasso se procede a una larga presentación de la situación previa al asedio. Se reducen también las complicadas operaciones bélicas del italiano a una batalla final. Frente a la obra épica, en la más moderna no hay ni viajes ni catálogos ni desfiles, y, en general, como es lógico, las descripciones quedan reducidas al mínimo, siempre en función de las exigencias del género dramático.

Como ya indicara Arata, se ha operado una decidida refundición de la que "quedan excluidos todos los episodios -y eran los más sabrosos del poema- que tenían como argumento las rencillas y aventuras privadas de los caballeros cristianos" (p. 24), que tantas veces se mezclaban con la trama bélica. No sólo se elimina lo particular, sino además todo lo que resulta sensual o poco edificante, mientras que se crean nuevos personajes -Charles, Fabricio, Enrique- que encarnan la empresa cristiana (p. 25), con tanta frecuencia soslayada por Tasso en sus excursos imaginativos y novelescos. De los sueños de los personajes italianos queda sólo uno: precisamente el que anuncia la muerte de Clorinda la noche del sabotaje contra las máquinas cristianas, que el poema nos ofrece en el canto XII. Nuestro autor parece reforzar la idea de la cruzada por encima de todo y en ese empeño también deja al margen de su recreación los sucesos mágicos y buena parte de las aventuras amorosas. En concreto, el anónimo elimina al nigromante y consejero Ismeno del canto II, otro personaje inventado por Tasso, aunque conserva la historia de la imagen santa por partida doble robada y trae a colación a otro mago, Marsenio, que efectúa él mismo el robo de la figura mariana. Asimismo, omite a Solimano, protagonista de varios episodios más fantásticos que históricos. Se mantiene la oferta de los egipcios de que, a cambio de protección, no ataquen a sus aliados de Jerusalén; la tregua la pide Argante junto a

13 Versión esp., Barcelona, Labor, 1951 [1925], p. 124. 
Clorinda, y no sólo él. Godofre, que no declaraba la guerra en la obra del ferrarés, sí lo hace en la pieza española; en la contienda se enfrenta mortalmente a Clorinda y Tancredo en lugar de a éste con Argante, como sucedía en el canto XIX de la Gerusalemme. Éstos sólo luchan una vez en la refundición, mientras que Tasso había relatado tres enfrentamientos de Clorinda con los cristianos (en los cantos III, VI y XII). Y, por supuesto, el dramaturgo sólo retiene, de las diversas historias eróticas del poema italiano, un doble enredo amoroso, el de Clorinda, Tancredo y Erminia, que sirve para vertebrar su trama fronteriza y que puede tener un parecido con los típicos argumentos moriscos tan del gusto de los españoles del XVI.

Muy cerca del pasaje que nos importa aquí, nuestro anónimo reduce a uno solo los dos episodios tassianos de destrucción de las máquinas cristianas, pues, en el canto XI, hacia la mitad del poema, los musulmanes habían destruido algunas de ellas sin intervención de Clorinda, mientras que en el canto XII esa brava guerrera sale de noche con Argante, como en la comedia, a quemar la más importante torre móvil de los asaltantes. El infortunado final de la valerosa mora es el mismo en ambas piezas, pero el relato corre en la más antigua a cargo del viejo Arsete, eliminado después por el español en beneficio de Argente. Tampoco se desarrolla el sutil cambio final de Clorinda que se observa en Tasso: ni ella implora el perdón de Tancredo ni siente miedo ni se transfigura al volverse cristiana, sino que, de un modo un tanto mecánico, pide ser bautizada como para cumplir la profecía del sueño de su acompañante y fallecer en tan sólo unos minutos.

Recordemos, por vía de contraste, parte del resumen analítico que del canto doceavo de la Gerusalemme hacía un especialista en Tasso como es el ya citado L. Caretti, síntesis que de paso permite observar algunos cambios menores que operara el autor anónimo de La conquista: "Dopo un canto di ampia struttura corale e scenografica, la poesia del Tasso torna a concentrarsi sopra uno dei grandi personaggi del poema, e ritrovando cosí la propria misura interiore si rifa, da descrittiva e rappresentativa, intensa e drammatica. È infatti il canto di Clorinda, della morte e trasfigurazione di Clorinda: in brevissimo spazio di tempo, tra le ultime tenebre della notte e le prime luci del alba, si compie il fatale destino della giovane donna, preannunciato da un sogno tristemente profetico. In una tessitura narrativa nervosamente scattante, con una progressione ritmica via via sempre piú celere e concitata, si consumano gli atti estremi di un'esistenza intrepida e generosa: 1'audace sortita di Clorinda e Argante da Gerusalemme per incendiare di soppiatto la grande torre mobile, l'allarme e la reazione dei cristiani, il vano tentativo di rientrare occultamente entro le mura, 1'inseguimento dell'ignaro Tancredi e il notturno combattimento, il tragico epilogo e il doloroso riconoscimento, la dichiarazione di fede, il battesimo e la mirabile morte" 14 .

Pero a esta síntesis sigue una reflexión más detenida del mismo crítico, que

${ }^{14}$ Ed. cit., p. 354. 
citamos también por extenso y en la que se desvela la técnica de Tasso y es posible que también la razón primera de que el dramaturgo español eligiese el episodio para su adaptación, esto es, su dramatismo: "Clorinda sino a questo momento era figura singolarmente dimidiata: ora vergine guerriera a fianco di altri guerrieri, come la virgiliana Camilla e l'ariostesca Marfisa, ed ora invece creatura della fantasia innamorata di Tancredi, luminosa immagine di beltà femminile, apparizione tanto suggestiva quanto fugace. Soltanto alla vigilia della sua ultima impresa militare, e quindi nel corso drammatico delle vicenda e nel momento della morte, Clorinda acquista, come personaggio, una propria vita autonoma e un profilo compiuto, rivelando, al di là dei parziali schemi in cui era stata sinora costretta, la profonda complessità e la delicata sostanza affettiva del suo spirito. Il vero personaggio Clorinda nasce, vive e muore, dunque nel giro di poche ottave; e tuttavia la sua metamorfosi non è conversione immotivata ed estrinseca, né la sua fine tragica è espediente romanzesco o catastrofe puramente spettacolare. Il racconto del vecchio servo Arsete e il sogno premonitore provvedono infatti a creare, sin dall'inizio del canto, un'atmosfera di tragica sospensione, presagio di sventura imminente. Clorinda pertanto è già mutata, da quel che era, nel momento stesso in cui esce da Gerusalemme; e se continua ad obbedire all'antica legge militare in cui s'è educata, internamente però non è piú la indomita guerriera di prima, non è piú sicura di sé e della sua sorte, e s'intuisce per la prima volta smarrita e spaventata. Sí che quando, trafitta da Tancredi, implora il perdono e a sua volta lo concede all'avversario, e abbraccia la nuova fede e chiede il battesimo, e infine spira visibilmente trasfigurata, essa altro non compie che 1'ultimo atto di un processo di chiarificazione interiore che si è venuto svolgendo, progresivamente e coerentemente, dai funesti presagi dell'esordio sino all'estremo congedo concitato e franto. In verità il Tasso ha qui realizzato uno splendido esempio di poesia essenzialmente 'drammatica', tutta azione, movimento e dialogo, legando insieme momenti lirici, elegiaci e tragici, mediante transizioni concisamente veloci, innesti fulminei, scorci arditi e tagli perentori, lavorando mirabilmente di concentrazione e rinunciando a indugi analitici, pause divaganti, abbellimenti decorativi" 15

Es difícil que, en lo que nos interesa en estas páginas, la lectura paralela de los episodios concretos de Tasso y de la tercera jornada del texto teatral español no lleve a cualquier crítico a otra conclusión que no sea ésta: el autor teatral anónimo no se ha inspirado sino en el épico italiano. Es cierto que puede introducir algunas pequeñas variaciones respecto a los sucesos de éste, en los que no vamos a insistir más aquí, sobre todo porque responden a una simplificación teatral típica ${ }^{16}$. Pero el orden de los acontecimientos y su desarrollo en general son los mismos que los de Tasso.

\footnotetext{
15 De nuevo en ed. cit., pp. 354-355.

16 Por ejemplo, la suspensión del resultado de la intervención de Clorinda para salvar a los jóvenes cristianos llamados en la pieza teatral no Sofronia y Olindo sino Solinda y Eustaquio,
} 
Repasemos ahora el texto que nos interesa de la tercera jornada de La conquista de Jerusalén, en cuyos detalles críticos no vamos a entrar aquí. Y recordemos que, en primer lugar, el pasaje que aquí nos atañe contiene un relato o relación suscitado por las réplicas anteriores de los dos personajes presentes en escena:

ARGENTE Agora conocerás,

Clorinda, si con razón

temo de tu perdición

en esta verdad que oirás.

CLORINDA Di, que yo te escucharé

si largo el cuento no fuere ${ }^{17}$.

Unas frases a las que sigue el largo parlamento en romance de Argente, que citamos íntegramente, dado que se trata de un texto muy poco conocido y será necesario para las comparaciones que siguen:

Todo lo más que pudiere,

señora, lo abreviaré.

El senado rey de Etiopia,

que la ley cristiana guarda

de amor y de celos siente

el alma toda abrasada

por la reina su mujer,

morena pero agraciada,

de la cual fui yo su esclavo,

y como eunuco en su cámara

cual doncella la servía,

costumbre entre ellos usada.

Donde la reina dormía,

en una tabla pintada,

de modo que ese desenlace feliz ocurra en la segunda jornada y sólo se sepa por las palabras de la propia heroína. Ello puede responder a la búsqueda de cierto suspense dramático y, desde luego, la piedad sentimental de la Clorinda tassiana se transforma aquí más bien en frío cálculo.

${ }^{17}$ Pp. 93-94 de la ed. cit. Como en la cita posterior, conservamos los signos del editor y su numeración de los versos. 
un armado caballero

con hermoso rostro estaba

y una doncella hermosa

a quien una sierpe brava

con fiero error y semblante

crudamente amenazaba.

En esta mesma sazón

la reina estaba preñada.

Parió la reina, y el parto

fue una niña hermosa y blanca,

casi en todo semejante

a la que pintada estaba.

Confusa con miedo y triste

quedó la reina cuitada

viendo el parto hermoso y blanco

donde negro le esperaba,

y la condición celosa

del rey la tiene turbada.

Teme, si descubre el parto,

su cierta muerte y infamia.

En fin, tomó por remedio

en trocar su prenda amada

a una negra criatura

que recién nacida estaba.

Esto fue con tal secreto

que nunca el rey supo nada.

Entregome a mí la reina

la hija que tanto amaba

y rogome la trujese

donde la hiciese cristiana, pues hacerlo allí no pudo,

que su ley más tiempo manda.

Diome infinitas riquezas,

vertieron sus ojos lágrimas, 
y al caballero pintado

con tierno pecho rogaba.

$\mathrm{Y}$ al pasar de una floresta

vi una tigre divisada

y con el miedo subíme,

con el miedo en una haya,

dejando la criatura

en el suelo, a quien llegara

la fiera y con mansedumbre

a sus labios aplicara

los pechos de leche llenos,

cosa que contarlo espanta.

Fuese y sin lisión la deja

de hambrienta contenta y harta.

Del árbol bajé yo al punto

que apuntaba la mañana.

Tomé a seguir mi viaje

con la niña mal guardada

y a las orillas de un río

descubrí gente enseñada

a robos y a desafueros,

y a matar ejercitada.

Arrojeme luego al río,

y en una mano llevaba,

la niña alzada en el aire,

con la otra rompía el agua;

pero la rauda corriente,

mis fuerzas dibilitaba

y con temor de la muerte

otra vez solté la carga,

y agonizado y cansado

en fin a tierra llegara;

mas antes que yo llegase

ya la niña en tierra estaba, 
allí traída del cielo

que por su vida miraba.

$\mathrm{Y}$ aquella noche, entre sueños,

un fuerte miedo me asalta:

vi el armado caballero

que te [he] dicho de la tabla,

el cual con voz enojosa

y terrible así me habla:

“¿Por qué, Argente, no bautizas

a esa niña? ¿Por qué tardas?

Mas yo, que soy guardador

de su cuerpo y de su alma,

a pesar tuyo haré

que muera en la ley cristiana".

Desapareció al momento, pero yo no me di nada

-a trueco de verte mora-

de todas sus amenazas;

que tú eres, Clorinda bella,

esta niña desdichada,

que por tantas desventuras

has venido a ser honrada,

y por tu valor extraño

temida y reverenciada

de cuantos a sus oídos

llevó tu nombre la fama.

Esto he querido contarte

porque sé que lo inorabas

por pasarte en la niñez,

que lo demás no importaba.

Sólo me importa decirte

que esta noche a mí tornara

aquel caballero blanco

el cual dijo que es tu guarda, 


$$
\begin{aligned}
& \text { y me ha dicho qu'esta noche } \\
& \text { has de ser muerta y cristiana, } \\
& \text { y que esto será sin duda } \\
& \text { antes que amanezca el alba. } \\
& \text { Por esto, Clorinda mía, } \\
& \text { te ruego que allá no salgas } \\
& \text { al campo de los cristianos } \\
& \text { donde la muerte te aguarda }{ }^{18} \text {. }
\end{aligned}
$$

Entremos en algunos pormenores. La aparición de Clorinda va acompañada, según la acotación correspondiente de la segunda jornada, con detalles armamentísticos como "la tigre" pintada en el escudo que procede a todas luces del yelmo de la heroína en Tasso ("la tigre, che su l'elmo ha per cimiero": 2.38.5) y que es ahora bastante más visible para el público teatral. En concreto, leemos en la acotación del anónimo español:

Vanse, $y$ salen ALADINO REY, MARSENIO y ARGANTE moros, $y$ CLORIND $A$, armada, y un muchacho delante, que la trae el escudo y el yelmo, y pintada una tigre en el escudo, $y$ dice CLORIND $A^{19}$.

La psicología de Clorinda es mucho más plana en la obra escénica: arrogante, sin claros visos de piedad ni sentimiento. El eunuco pagano Argante, llamado también Argente en la pieza teatral ${ }^{20}$, cuenta la historia de Clorinda en la tercera jornada (vv.

${ }^{18}$ Pp. 94-96 de la ed. cit.

${ }^{19}$ Jorn. II, acot. al v. 94; p. 53 de la ed. cit.

20 Este nombre debe proceder del "circasso Argante" (2.59.1) de Tasso. Una de las preocupaciones del dramaturgo ha sido la de alterar los nombres de los personajes de esos episodios, excepto los de Clorinda y Tancredo. Hay que aclarar también que, en el manuscrito de Palacio, el nombre del personaje de Argante aparece unas veces así y otras copiado incorrectamente como Argente. Dado que éste último es el nombre de otro personaje de la comedia (véase jornada III, v. 686), ya Arata prefería uniformar en las acotaciones y en las réplicas la grafía, empleando la forma Argante para indicar el guerrero moro, y Argente para indicar el eunuco, ayo de Clorinda (véase su edición de 1992, p. 53, n. 35; y 2002, p. 76, n. 36). Por otro lado, en ese estragado manuscrito son varios los errores de copia que desfiguran los nombres de muchos personajes: Eriminia, Alcardo, Arnaldo. Y la explicación podría ser que el copista resolvió mal probablemente las abreviaturas del texto que copiaba -en el que figuraría simplemente $A r$ - y confundió así a dos personajes distintos, Argente y Argante. Las enmiendas pueden observarse en fols. 262r-v del códice (véanse también sobre este punto las ediciones de Arata de 1992, p. 93, 148; o de 2002, p. 109, n. 148). 
725 ss.) de un modo muy semejante a la historia en boca de Arsete en el poema, y su papel es equivalente. La anécdota coincide en diversos detalles y, como hemos dicho, en su orden: la fe cristiana de los reyes etíopes (aquí en singular, el rey "que la ley cristiana guarda": v. 727), el milagroso influjo de la "tabla pintada" (v. 738) en la concepción de Clorinda y su color blanco ${ }^{21}$, tabla en que están representados "un armado caballero" y "una doncella hermosa" (vv. 739-741); la condición celosa del rey, como en Tasso, que fuerza la solución desesperada que encuentra la reina para ocultar a la criatura, trocada, tal como lo era en el italiano también, por otra niña negra, y entregarla a Argante/Argente, con el ruego perentorio de que sea bautizada en cuanto sea posible, ruego no atendido por él; los episodios sucesivos de la tigresa que amamanta a la niña y los ladrones y la huida en el río; los dos sueños, uno en aquel entonces y otro la noche antes del funesto desenlace de la aventura final de Clorinda, en los que el misterioso caballero muestra su irritación con el eunuco por el incumplimiento del sacramento del bautismo, con profecía sobre la muerte de la heroína; las vestimentas negras de Clorinda; el episodio del incendio de la torre (Tasso) y las máquinas bélicas 22 en la pieza teatral y la muerte de Clorinda, que el dramaturgo convierte en una escena con Tancredo, con la obligada conversión de la joven pagana en brazos de aquél.

Incluso algunas diferencias marcadas por Tasso frente a Heliodoro se repiten en la obra dramática. Por ejemplo, esa simplificación de los sucesivos personajes que en éste último toman a su cargo la protección de Cariclea, reducidos en el épico renacentista y en la obra supuestamente cervantina a la figura única y bastante plana de Arsete/Argante/Argente.

${ }^{21}$ Aunque sea sólo de pasada, podemos mencionar aquí que autores del XVII como Huarte de San Juan en su Examen de ingenios (cap. XV, 3) y Sebastián de Orozco en El libro de los proverbios glosados alteran este motivo al hacer que sea una mujer blanca la que da a luz un niño negro, si bien se conserva la causa: en el momento de concebirlo contempla un cuadro de un etíope que cuelga en su cuarto. El asunto se complica, en primer lugar, porque en el folclore hay muchas noticias sobre embarazos extraños y portentosos, pero es probable que esos autores cultos hayan tenido presente el relato de Heliodoro, y, en segundo lugar, porque existe ya alguna versión medieval, como la que se lee en El collar de la paloma de Ibn Hazm de Córdoba, que en su capítulo I recoge la inversión citada: de padres blancos una criatura negra y por la misma razón aludida. Pueden verse detalles y discusión del tema en J. González Rovira, La novela bizantina de la Edad de Oro, Madrid, Gredos, 1996, p. 102, e "Imaginativa y nacimientos prodigiosos en algunos textos del Barroco", Criticón, 69 (1997), pp. 21-31, en este segundo trabajo encuadrando el tema en el más amplio del tópico de cómo la imaginación puede alterar la naturaleza. Debido a estos problemas, González Rovira llega a dudar de que se trate siempre de la influencia de Heliodoro. El autor ha anunciado un trabajo futuro sobre este tema con el título "Del color de los etíopes", pero en su bibliografía posterior que conocemos no se encuentra mencionado.

${ }^{22}$ Cf. ya "las máquinas levantadas / de los soberbios cristianos": Jorn. III, vv. 691 s. 
Una de las preocupaciones a que hemos atendido en nuestros dos artículos citados es la defensa de una fecha más temprana de la que es usual aceptar para el conocimiento de Heliodoro por parte de Cervantes. Aquí se puede sospechar que es muy difícil que, si el autor del drama hubiese conocido a Heliodoro, no hubiera introducido algún dato proveniente de modo directo de éste y no de Tasso. Pero creemos que no existe ese dato, luego su relación es estrictamente con el italiano. Si esta obra es, como parece, bastante temprana, esto tiene pleno sentido; no lo tendría si hubiera otras razones para creer que es una pieza compuesta o reelaborada en una fecha más tardía, dentro ya del siglo XVII. Dado que la cronología establecida por Arata y confirmada por nosotros es muy segura y apunta al terminus ante quem de 1582, hay que pensar que en esos años este hipotético pero muy probable Cervantes, recién liberado del cautiverio argelino, se entrega a la escritura de sus primeras piezas teatrales y redacta La conquista de Jerusalén sin conocer todavía la novela de Heliodoro, que tanta influencia va a tener en su posterior producción.

Cuestión muy distinta y que no nos atañe aquí es la de a qué otras lecturas de Tasso pudo proceder este probable Cervantes y en particular si a la de sus tratados teóricos y más todavía en estas fechas tempranas ${ }^{23}$. Lo que nos importa es que sin la menor duda conocía bien la Gerusalemme y supo extraer de ella la inspiración para su pieza teatral

Máximo Brioso Sánchez y

Héctor Brioso Santos

Máximo Brioso Sánchez

mbrioso@us.es

Departamento de Filología Griega y Latina

Facultad de Filología

Universidad de Sevilla

C/ Palos de la Frontera s. n.

E-41004 - Sevilla
Fecha de recepción: 03/03/2008

Fecha de aceptación: 08/04/2008

23 Cf. La opinión muy negativa de Daniel Eisenberg en sus Estudios cervantinos, Barcelona, Sirmio, 1991, pp.37-56. 